\section{ALTOGETHER MANAGEABLE}

Sir, having just finished an 18-month placement as an oral and maxillofacial senior house officer (OMFS SHO) I was particularly delighted to read the excellent article in July's edition, An evaluation of senior house officer training in oral and maxillofacial surgery. ${ }^{1}$ As one of the respondents to their survey, it would appear from the results that I had the 'average' experience of an OMFS SHO, on most accounts. However, my personal experience as an SHO included one 'bleep-free' training session (1.5 hours) per week which provided an open forum to discuss cases and the management of many OMFS situations. Although this may not be the norm, it certainly added to the educational value of the post, and where feasible, is an invaluable asset to any SHO/DF2 placement, especially in the initial stages of the steepest learning curve you can possibly imagine.

I understand the difficulty providing a standardised OMFS SHO training programme as it is only in speaking to my fellow senior house officers that one realises how varied rotas, duties and exposures to specialist interests in that particular unit may be. Realistically, being a medical specialty, most "competencies' as mentioned in the above article could be directly observed by any medically trained senior clinician on the ward, ie not necessarily of the maxillofacial variety. With the advent of electronic logbooks (online portfolios) to record one's completion of procedures then and there, this seems a relevant, reasonable and altogether manageable method of improving learning outcomes for senior house officers.

\section{N. E. O'Murchu, Glasgow}

1. Stancliffe H, Little R, Keith D, Durham J. An evaluation of senior house officer training in oral and maxillofacial surgery. Br Dent J 2011; 211: 75-80.

DOI: 10.1038/sj.bdj.2011.773

\section{UPHOLDING STANDARDS}

Sir, your recent editorial, Lessons from a Greek roadmap (BDJ 2011; 211: $149)$ has raised a concern that I have about our, ie the UK, and indeed, your relationship with those people who are unfortunate enough to live in Euroland.

I fully understand your difficulties with navigating; may I recommend the maps produced by a well-known tyre maker (if they have ventured that far south) or indeed ask that you, as Editor-in-Chief of our esteemed journal, consider taking your holidays in future, solely for reasons of your personal safety, in regions that are better surveyed.

But, that said, I am concerned that you have not upheld the standards that I, and members of the BDA would expect from an Editor-in-Chief.

You refer to your pleasant day on the beach and in returning for dinner in AN hotel where you were probably the only British persons present, you write that you were 'DRESSED FOR LEISURE'. Surely, Sir, this is most inappropriate and, I regret to say, also a poor reflection on Euroland inhabitants. As a Great British person, and Editor-inChief of the $B D J$, is black tie for dinner when 'abroad' too much to ask?

Is it any wonder that these poor souls find themselves in the current financial predicament without such standards to uphold?

S. Geddes, Wales

DOI: 10.1038/sj.bdj.2011.774

\section{FACIAL SWELLINGS}

Sir, a 72-year-old female presented to her general medical practitioner with an acute onset (over four hours) of facial angioedema (AE) involving the tongue, lips and floor of mouth. She had been on Lisinopril for four months for treatment of hypertension. On examination, her upper lip was significantly swollen to at least double the normal size (Fig. 1).

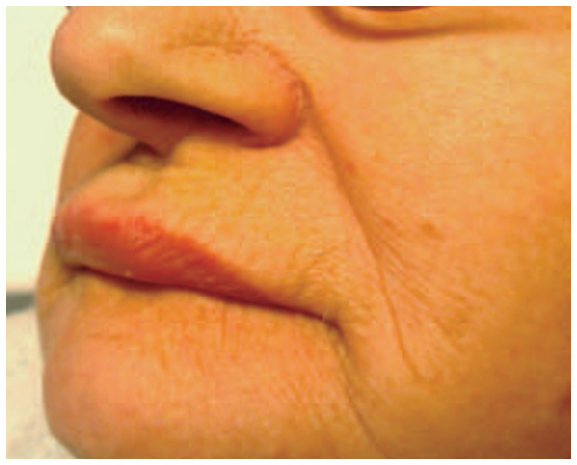

Fig. 1 Diffuse painless swelling of the upper lip

Her airway was not compromised and she had no other symptoms.

There were no other identifiable causes of the AE and the patient made a rapid recovery overnight with oral steroid and antihistamine treatment Lisinopril was changed to a calcium channel blocker alternative.

Angioedema (AE) often presents as facial swelling, but can progress to involve the tongue, oropharynx and supraglottic regions. Although classified as a rare side effect, AE is associated with the use of angiotensin converting enzyme inhibitors (ACEI) such as Lisinopril.

The onset of AE with the use of ACEI can range from within the first 3-4 weeks to several years of treatment. ${ }^{1}$ High risk groups include AfroCaribbeans, those older than 65 years of age and patients with known drugrelated allergies. ${ }^{2}$

Patients who present to general practice with facial swelling with no obvious oral-dental disease should have their past medical history checked and in particular the use of ACEI should be highlighted as a possible cause.

\section{A. Ujam, J. Maryosh, Kent}

1. Sondhi D, Lippmann M, Murali G. Airway compromise due to angiotensin-converting enzyme inhibitor-induced angioedema: clinical experience at a large community teaching hospital. Chest 2004; 126: 400-404.

2. Kostis J B, Kim H J, Rusnak J et al. Incidence and characteristics of angioedema associated with enalapril. Arch Intern Med 2005; 165: 1637-1642.

DOI: 10.1038/sj.bdj.2011.775

\section{WHOLLY UNSUPPORTIVE}

Sir, your correspondent S. Ramaraj (BDJ 2011; 211: 151) reflects on cultural insensitivities. I would reflect that managerial insensitivities are not always culturally rooted.

My mother was herself terminally ill when my father was diagnosed with terminal cancer in July 2004. I was working in a salaried NHS post at that time and my immediate clinical manager was on maternity leave. I requested of the dental service's interim general manager to be able to travel (300 miles) to be with them as soon as my work schedule allowed. This worked out to be in early September. Leave was immediately granted on the strength of relative urgency and its definition would be sorted when I returned. I agreed to keep in touch while away from work.

Sadly, my father passed away the day I travelled in September and his 